\title{
The Predictability of Interdecadal Changes in ENSO Activity and ENSO Teleconnections
}

\author{
Scott Power, Malcolm Haylock,* Rob Colman, and Xiangdong Wang \\ Bureau of Meteorology, Melbourne, Australia
}

(Manuscript received 1 March 2005, in final form 22 September 2005)

\begin{abstract}
El Niño-Southern Oscillation (ENSO) in a century-long integration of a Bureau of Meteorology Research Centre (BMRC) coupled general circulation model (CGCM) drives rainfall and temperature changes over Australia that are generally consistent with documented observational changes: dry/hot conditions occur more frequently during El Niño years and wet/mild conditions occur more frequently during La Niña years. The relationship between ENSO [as measured by Niño-4 or the Southern Oscillation index (SOI), say] and all-Australia rainfall and temperature is found to be nonlinear in the observations and in the CGCM during June-December: a large La Niña sea surface temperature (SST) anomaly is closely linked to a large Australian response (i.e., Australia usually becomes much wetter), whereas the magnitude of an El Niño SST anomaly is a poorer guide to how dry Australia will actually become. Australia tends to dry out during El Niño events, but the degree of drying is not as tightly linked to the magnitude of the El Niño SST anomaly. Nonlinear or asymmetric teleconnections are also evident in the western United States/northern Mexico. The implications of asymmetric teleconnections for prediction services are discussed.

The relationship between ENSO and Australian climate in both the model and the observations is strong in some decades, but weak in others. A series of decadal-long perturbation experiments are used to show that if these interdecadal changes are predictable, then the level of predictability is low. The model's Interdecadal Pacific Oscillation (IPO), which represents interdecadal ENSO-like SST variability, is statistically linked to interdecadal changes in ENSO's impact on Australia during June-December when ENSO's impact on Australia is generally greatest. A simple stochastic model that incorporates the nonlinearity above is used to show that the IPO [or the closely related Pacific Decadal Oscillation (PDO)] can appear to modulate ENSO teleconnections even if the IPO-PDO largely reflect unpredictable random changes in, for example, the relative frequency of El Niño and La Niña events in a given interdecadal period.

Note, however, that predictability in ENSO-related variability on decadal time scales might be either underestimated by the CGCM, or be too small to be detected by the modest number of perturbation experiments conducted. If there is a small amount of predictability in ENSO indices on decadal time scales, and there may be, then the nonlinearity described above provides a mechanism via which ENSO teleconnections could be modulated on decadal time scales in a partially predictable fashion.
\end{abstract}

\section{Introduction}

The El Niño-Southern Oscillation (ENSO) phenomenon affects climate over many parts of the world (Ropelewski and Halpert 1989; Philander 1990; Halpert and Ropelewski 1989), including Australia (Nicholls

* Current affiliation: Climatic Research Unit, University of East Anglia, Norwich, United Kingdom.

Corresponding author address: Dr. Scott B. Power, Bureau of Meteorology Research Centre, GPO Box 1289K, Melbourne VIC 3001, Australia.

E-mail: s.power@bom.gov.au
1992; Allan 1991; Power et al. 1998a). El Niño (La Niña) tends to increase the risk of dry (wet) conditions across many parts of Australia, and the economic cost of Australian droughts often associated with ENSO is believed to run into hundreds of millions of dollars (Nicholls 1992; White 2000). Managerial strategies based on ENSO forecasts could help reduce this, with greater savings expected for more skillful forecasts (Adams et al. 1995).

ENSO and its teleconnections vary on decadal and longer time scales in observations (e.g., Wang and Ropelewski 1995; Allan et al. 1996; Wang and Wang 1996; Kestin et al. 1998; Gershunov and Barnett 1998; Power et al. 1999a; Mann et al. 2000; McCabe and Det- 
tinger 1999; Hasegawa and Hanawa 2003; Kiem and Franks 2004; Kiem et al. 2003; Verdon et al. 2004; McKeon et al. 2004a) and coupled models (e.g., Knutson and Manabe 1998; Walland et al. 2000; Arblaster et al. 2002; Vimont et al. 2002; Hunt and Elliott 2003).

Decadal variability can arise for numerous possible reasons. For example, instabilities in the atmosphere can drive internal atmospheric variability on time scales up to and beyond a decade (James and James 1992) and this can drive surface flux variability that alters surface climate (Frankignoul and Hasselmann 1977; Power et al. 1995; Frankignoul et al. 1997), ENSO variability and predictability (e.g., Battisti and Hirst 1989; Kleeman and Power 1994; Blanke et al. 1987; Moore and Kleeman 1999; Thompson and Battisti 2000; Burgers 1999; Penland and Sardeshmukh 1995), and ENSO statistics (e.g., Chu and Katz 1985; Kestin et al. 1998). Some of the decadal variability in the Tropics may have a subtropical or extratropical origin (e.g., Hazeleger et al. 2001; Liu et al. 2002; Wu et al. 2003; Galanti and Tziperman 2003; Nonaka et al. 2002; Kleeman et al. 1999; Lysne et al. 1997; Lohmann and Latif 2005; White et al. 2003; Meehl and $\mathrm{Hu}$ 2006; Barnett et al. 1999; Pierce et al. 2000; Liu et al. 2002; White et al. 2003; Kleeman et al. 1999; Nonaka et al. 2002; Lohmann and Latif 2005). Other studies suggest that some of the decadal variability in ENSO might be generated within the tropical Pacific without the need for decadal boundary forcing through nonlinear mechanisms (e.g., Münnich et al. 1991; Jin et al. 1994; Tziperman et al. 1994; Timmerman and Jin 2002; Liu et al. 2002). Instabilities (e.g., eddies, tropical instability waves) present in the ocean might also help to drive some variability on decadal time scales in analogy with instabilities in the atmosphere (e.g., James and James 1992). See Power and Colman (2006), Kleeman and Power (2000), Miller and Schneider (2000), Miller et al. (2003), and Working Group 2 (2004) and Working Group 3 (2004) for further discussion. Other drivers of decadal climate variability (e.g., intermittent volcanic activity, irradiance variability, changes in greenhouse gases and sulfate aerosols) have been discussed elsewhere (e.g., Houghton et al. 2001 and references therein).

The results obtained by Power et al. (1999a) are of particular interest to this study. They documented interdecadal variability in the association between the Southern Oscillation index (SOI) and year-to-year changes in rainfall, maximum surface temperature, and the wheat crop yield all averaged over the entire country ("all Australia"), and volume transport in the Murray River in southeastern Australia. They showed that the variance of year-to-year changes in the SOI and the association between the SOI and these Australian cli- mate-related variables (tracked using correlation coefficients between the SOI and the Australian climate variables in 13-yr running blocks) waxed and waned during the twentieth century in conjunction with the Interdecadal Pacific Oscillation (IPO). They used the term IPO to describe the observed ENSO-like or El Niño-like sea surface temperature (SST) pattern that emerged in the analysis of near-global interdecadal sea surface temperature variability by Folland et al. (1999). Power et al. (1999a) showed that the index for the IPO is very similar to the interdecadal component of an index for the Pacific Decadal Oscillation (PDO) discussed by Mantua et al. (1997). Folland et al. (2002) discussed additional evidence supporting the view that the PDO can be regarded as the North Pacific-wide manifestation of the IPO. Power et al. (1999a) used Monte Carlo experiments to establish that the modulation of ENSO teleconnections by the IPO was statistically significant at the $95 \%$ (rainfall, temperature, crop yield) and $90 \%$ (river flow) levels. They also showed that interdecadal changes in the skill of an ENSO-based forecast scheme were coherent with the IPO. Increased understanding of decadal variability therefore has the potential to improve our ability to predict seasonal-tointerannual climate predictions.

If interdecadal variations in climate associated with the IPO are predictable, and the changes in ENSO and its impact are actually physically driven and dominated by the IPO, then interdecadal changes in ENSO and its teleconnections should also be predictable to some extent. If this is the case, then forecasters could use indices for the IPO or PDO to improve statistical prediction schemes (e.g., Latif and Barnett 1994; Power et al. 1999a; McKeon et al. 2004b). On the other hand, the modulation might simply reflect unpredictable changes in the atmosphere and ocean that are driven by internally generated, chaotic atmospheric variability (Pierce 2002). Interdecadal changes in correlation coefficients can also occur by chance and so it may be that the association between the IPO and ENSO teleconnections might simply represent a statistical fluke.

The main purpose of this paper is to help clarify these issues by examining the predictability of interdecadal changes in ENSO and its teleconnections in the observations and Bureau of Meteorology Research Centre (BMRC) coupled general circulation model (CGCM). To help understand the apparent influence of the IPO on the degree to which ENSO effects Australian climate, we will examine the statistical relationship between ENSO indices and Australian rainfall. We will see that the relationship in both observations and the CGCM is nonlinear and that this nonlinearity partially determines the apparent interrelationship between the 
IPO and ENSO's impact on Australian climate. A simple stochastic model is used to show that nonlinearity can actually increase the likelihood of apparent interdecadal modulation, even in the absence of predictability beyond $1 \mathrm{yr}$.

The CGCM is described in section 2. ENSO and Australian rainfall variability in the CGCM is briefly described in section 3 . The predictability experiments are described in section 4 . The nonlinear relationship between ENSO and Australian climate is discussed in section 5 and the nature of the IPO-PDO is discussed in section 6. We will see that the IPO and PDO indices can be largely, though not entirely, understood as proxy records for the interdecadal variability evident in traditional ENSO indices. The extent to which ENSO teleconnections are modulated by the IPO is assessed in section 7. The main results are summarized and discussed in section 8 .

\section{The BMRC coupled GCM}

The model used here is based on a version of the BMRC coupled atmosphere-ocean-sea ice model described by Power et al. (1998b), BCM2.2 (BCM = BMRC CGCM). The performance of BCM2.0 (an earlier but closely related version) in the Tropics has been examined in two climate model intercomparison projects: the Study of Tropical Oceans in Climate Models (STOIC; Davey et al. 2002) and the ENSO Simulation Intercomparison Project (ENSIP; Latif et al. 2001). A version of this model with changes made to some of the atmospheric parameters (BCM2.1) was used for seasonal-to-interannual forecasting in the Bureau of Meteorology (Wang et al. 2000) between 1999 and 2003.

The current version (BCM2.2) has an improved atmospheric GCM (AGCM) and uses flux adjustment. The AGCM is called the BMRC unified atmospheric model (BAM). In BCM2.2 BAM is run at a horizontal resolution of rhomboidal wave 21 , with 17 vertical levels (increased from 9 levels in both BCM2.0 and BCM2.1). Shortwave radiation is parameterized following Lacis and Hansen (1974). The longwave radiation scheme used is a modified version of the FelsSchwarzkopf scheme developed at the Geophysical Fluid Dynamics Laboratory (GFDL) (Schwarzkopf and Fels 1991). Penetrative, midlevel, and shallow convection are parameterized using the mass flux scheme of Tiedtke (1989). The model has surface boundary layer parameterizations based on the formulations of Louis (1983). Oceanic evaporation is enhanced over low-wind regions according to the formulation of Miller et al. (1992). Vertical diffusion also follows the stabilitydependent form of Louis (1983) as modified by McAvaney and Hess (1996). Soil moisture is represented by a single-layer "bucket" model with a field capacity of $150 \mathrm{~mm}$ after Manabe and Holloway (1975). Gravity wave drag is determined using the formulation of Palmer et al. (1986).

The atmospheric component includes the Rotstayn (1997) prognostic cloud scheme for stratiform clouds. Features of the scheme include two prognostic variables (cloud liquid water and ice) with a physically based treatment of associated cloud microphysical processes. A triangular probability function is assumed for the subgrid-scale distribution of moisture within a grid box. Cloud formation is based on the statistical condensation scheme of Smith (1990). Clouds are permitted at all model levels, except the lowest. An additional diagnostic treatment of convective clouds is included, with the fraction of cloud based on the convective rainfall rate. There is currently only vertical advection of cloud water variables by the model dynamics. Details of the atmospheric model climate are given by Colman et al. (2001) and Colman (2001). The atmospheric model was integrated for $5 \mathrm{yr}$ prior to coupling.

The ocean component of all three BCM models is a global version of the GFDL Modular Ocean Model (MOM; Pacanowski et al. 1991; Power et al. 1995). MOM is a primitive equation model, based on the earlier work of Bryan (1969), which makes use of the rigidlid, Boussinesq, and hydrostatic approximations (e.g., Gill 1982). The meridional spacing varies from $0.5^{\circ}$ within $7^{\circ}$ latitude of the equator, from where it gradually increases to a maximum of $5.8^{\circ}$ near the North Pole. The longitudinal spacing is a constant $2^{\circ}$ for the whole globe. There are 25 levels in the vertical, with 12 in the top $185 \mathrm{~m}$. The level thicknesses range from $15 \mathrm{~m}$ near the surface to nearly $1000 \mathrm{~m}$ near the bottom. The maximum depth is $5000 \mathrm{~m}$. The flux of heat and salt through sidewalls and the bottom is set to zero. No-slip boundary conditions are used along all sidewalls. Bottom friction is parameterized as a quadratic function of the lower velocity, with a constant $10^{\circ}$ turning angle. The bathymetry represents a smoothed approximation to the high-resolution dataset of Gates and Nelson (1975). There are 82 grid points from south to north and 182 grid points for west to east. Additional islands incur a significant cost in this version of MOM and so only Australia (combined with New Guinea), New Zealand, and Antarctica are separated from the remaining land points. There is no Bering, Gibraltar, or Torres Strait. Drake Passage was artificially widened to aid throughflow of the Antarctic Circumpolar Current. The Indonesian Throughflow was also artificially widened to reduce current speeds that threatened to become unstable. Some of the near-coastal depths were increased to avoid sharp jumps in depth that can lead to numeri- 
cal problems associated with topographic waves (Killworth 1987).

The vertical diffusion is determined via a mixing scheme based on the method described by Chen et al. (1994), designed for an isopycnal model of the tropical Pacific. The scheme was modified to operate in the fixed-level model used here. The scheme has two parts: a turbulent kinetic energy equation for the surface mixed layer, and a gradient Richardson numberdependent scheme for the ocean interior. A time step of $1200 \mathrm{~s}$ is used on the barotropic, baroclinic, and tracer equations. The ocean model was spun up for several hundred years prior to coupling. The sea ice model is a version of the zero-layer Semtner (1976) thermodynamic model (see also Colman et al. 1992).

As mentioned above, BCM2.2 incorporates flux adjustments whereas earlier versions did not. Adjustments are made to three fields: net surface heat flux, net surface freshwater flux, and the penetrating shortwave component of the heat flux. Monthly varying flux adjustment fields are used, to ensure the veracity of the seasonal cycle. No flux adjustments are applied to surface stresses.

For this study BCM2.2 was integrated for $200 \mathrm{yr}$ and the last $100 \mathrm{yr}$ are analyzed here. The model exhibits some residual climate drift [i.e., spurious climate drift that occurs despite the use of flux adjustments; Power (1995)], but the magnitude is greatest near the start of the run and is therefore omitted. Output from BCM2.2 was contributed to the Coupled Model Intercomparison Project (CMIP) phase 2.

\section{ENSO and Australian rainfall variability in the CGCM}

The ENSO in the model and its teleconnections have been discussed by Wu et al. (2002) and AchutaRao and Sperber (2002). ENSO variability is clearly evident in the CGCM and represents the major mode of variability on interannual time scales in the Indo-Pacific. This is illustrated in Fig. 1, which shows (a) the spatial structure and (b) the time series of the first empirical orthogonal function (EOF) of unfiltered Indo-Pacific SST in the CGCM. While the variability and time scales are in broad agreement with the observations, there are some differences. For example, the modeled variability is weaker than observed. The standard deviations of annual time series of Niño-3, Niño-4, and Niño-3.4 are $0.67^{\circ} \mathrm{C}$ observed, $0.3^{\circ} \mathrm{C}$ modeled; $0.55^{\circ} \mathrm{C}$ observed, $0.34^{\circ} \mathrm{C}$ modeled; and $0.64^{\circ} \mathrm{C}$ observed, $0.34^{\circ} \mathrm{C}$ modeled, respectively. The observed values were calculated using National Centers for Environmental Prediction indices for the period 1950-2004, while the CGCM figures are based on the 100-yr control run. The modeled variabil- ity is displaced too far to the west and it is more biennial than observations suggest it should be (AchutaRao and Sperber 2002; Wu et al. 2002). Wu et al. (2002) also showed that the probability density functions of ENSO indices tended to be less skewed than their observational counterparts.

Bettio et al. (2003) discussed the dynamics of the ENSO in the model, as part of a much more detailed ongoing investigation. They noted that all of the major components of two leading paradigms for ENSO are present in the model. The paradigms are the delayed action oscillator (DAO; Schopf and Suarez 1988a,b; Battisti and Hirst 1989; Cane et al. 1990; Neelin et al. 1998) and the recharge-discharge oscillator (Jin 1997). See Wang (2001) and Dijkstra and Burgers (2002) for further discussion of the two theories.

A positive feedback arising from interactions between equatorial Pacific SSTs and the zonal wind stress, required by both theories, is evident in the CGCM. Equatorially trapped Kelvin and Rossby waves are fundamental to the DAO and they also play a major role in the CGCM ENSO. Finally, the north-south movement of heat onto and away from the equator is central to the recharge-discharge theory, and this is also a major feature of the CGCM ENSO.

ENSO is a major driver of climate variability over Australia in the model, as it is in the real world. This is illustrated in Fig. 2, which shows Niño-4 and allAustralia rainfall from the 100-yr integration. The data depicted represent averages over each calendar year and over the entire country.

Observed all-Australia indices are used for comparison. These indices are calculated by the National Climate Center and are based on annual and Australiawide averages of gridded rainfall and temperature data. The gridded rainfall dataset (Jones and Weymouth 1997) consists of monthly averaged rainfall on a regular $1^{\circ}$ by $1^{\circ}$ latitude-longitude grid covering the Australian continent for the period January 1900-December 2004 inclusive. The temperature dataset used consists of monthly mean anomalies of the daily maximum temperature on the same grid as rainfall but for only $55 \mathrm{yr}$ starting in January 1950 (Jones 1999). This set was generated using the Barnes successive correction technique (Koch et al. 1983) applied to high-quality temperature data (Della-Marta et al. 2004) from 99 stations.

Annual data and all-Australia variables like these have been used successfully in numerous previous studies (e.g., Nicholls et al. 1996; Power et al. 1998a,b, 1999a,b). The success of this simple approach in the Australian context partially lies in the fact that El Niño's (La Niña's) dominant impacts across Australia tend to be of one sign. They also tend to be dominated 
(a)

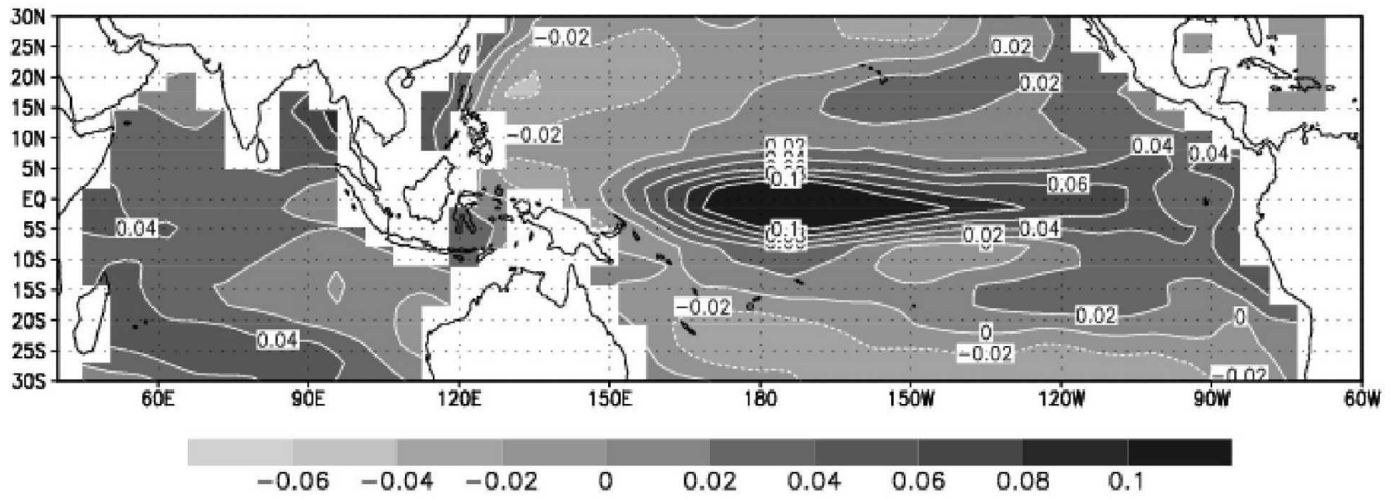

(b)

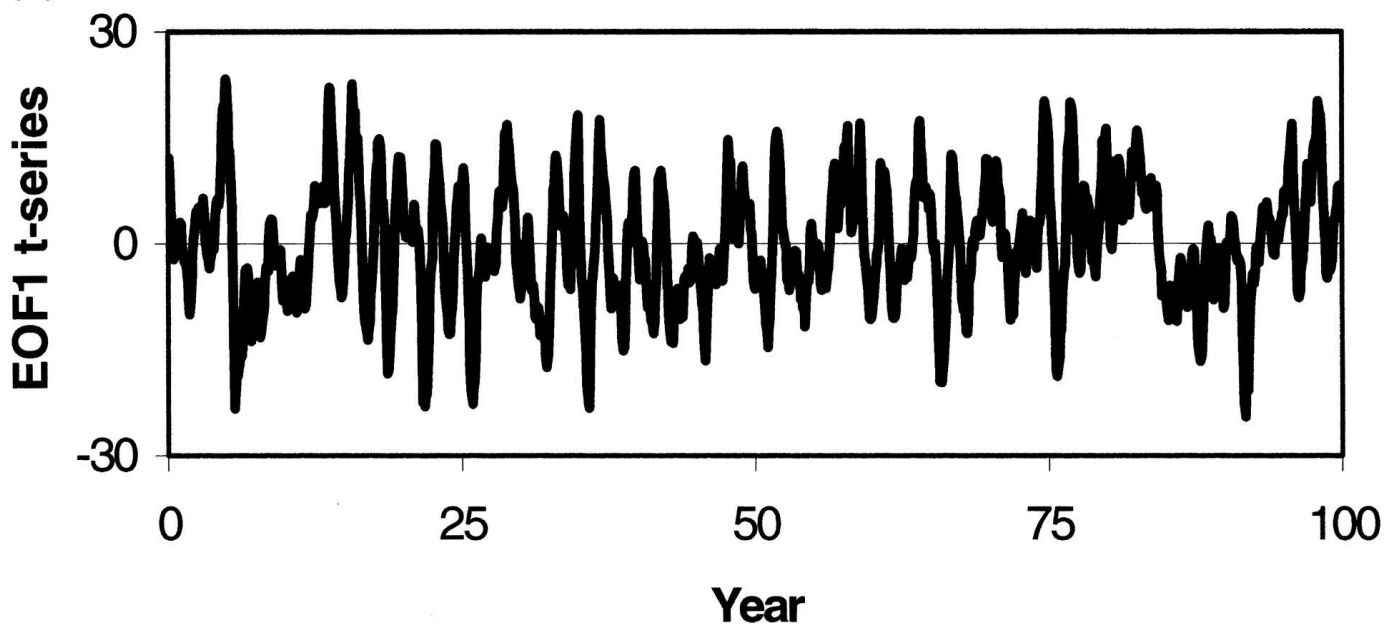

FIG. 1. CGCM: (a) Spatial structure of the first EOF of Indo-Pacific SST and (b) its time series.

by anomalies that occur during June-December of El Niño and La Niña events, that is, within a calendar year.

The correlation coefficient between anomalies of Niño-4 and all-Australia rainfall over the entire 100-yr integration of the CGCM is -0.45 , which compares favorably with the observed value of -0.53 . This coefficient exhibits a great deal of interdecadal variability in the model. This is illustrated in Fig. 3a, which shows the correlation coefficient in 13-yr running blocks. The coefficient varies between -0.87 and +0.11 during the course of the run. The equivalent figures for the correlation coefficient between Niño-4 and the maximum daily surface temperature ( $T_{X}$, gray line) are -0.54 and +0.87 (the values shown in Fig. 3a have been multiplied by -1 ). The amount of variability ENSO has-its vigor-also varies on interdecadal time scales as it does in the observations. This is evident in Fig. 3b, which shows the standard deviation of year-to-year changes in Niño-4 in 13-yr running blocks. The standard deviations range between $0.20^{\circ}$ and $0.43^{\circ} \mathrm{C}$.

\section{Predictability of interdecadal changes in ENSO and its Australian teleconnections}

It may be that the climate system exhibits underlying predictable interdecadal variability that causes interdecadal changes in ENSO and its impact on Australia.

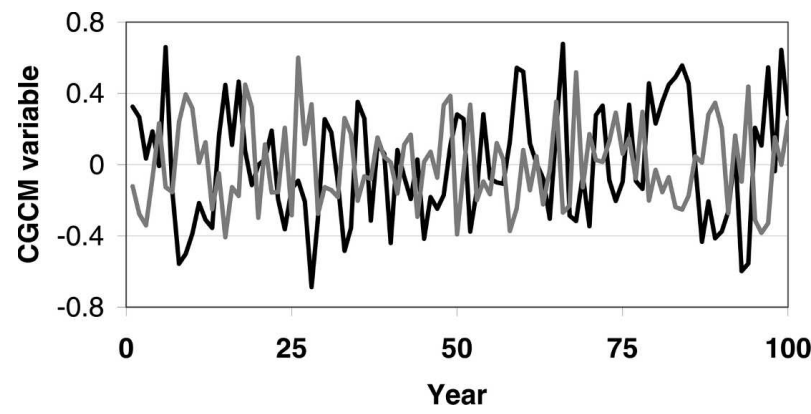

FIG. 2. CGCM: Standardized anomalies of all-Australia rainfall and Niño-4 from the 100-yr control run. The correlation coefficient between the two time series for the full $100 \mathrm{yr}$ is -0.45 . 

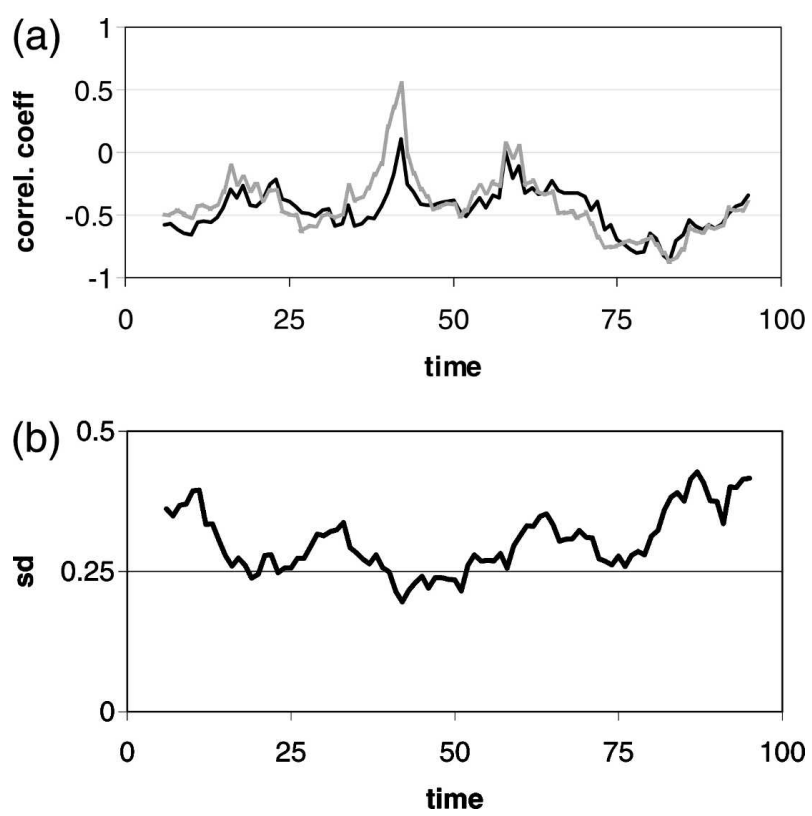

FIG. 3. CGCM: Time series of (a) the correlation coefficient between Niño-4 and both all-Australia rainfall $(R)$ and maximum daily surface temperature $\left(T_{X}\right)$ and (b) the standard deviation of Niño-4 (units: ${ }^{\circ} \mathrm{C}$ ), all calculated in 13 -yr moving blocks.

On the other hand, perhaps it is a random phenomenon that cannot be predicted. To estimate the degree of predictability we conducted four sets of perturbation experiments. The perturbation runs were initiated by swapping the initial atmospheric field with its counterparts a day or two earlier or later than the corresponding date in the control integration. The results are presented in Figs. 4a and 4b. Figure 4a shows the value of the correlation coefficient between Niño-4 and allAustralian rainfall (both annual averages) for the control and the four sets of 13-yr-long perturbation runs. The ensemble means are depicted as circles.

If the interdecadal variability in these ENSO-related statistics were predictable, then we would expect the values obtained in the perturbation runs to be similar to their control values. This is not the case. The values differ widely. The results suggest that the control values are not good guides to the values obtained in the corresponding perturbation experiments. This suggests that if there is any predictability in this statistic, then it is too small to be obvious in the relatively small number of perturbation experiments we were able to perform. The same is true for the predictability of interdecadal changes in the standard deviation of Niño-4 (Fig. 4b); the control values are a poor guide to their counterparts in the perturbation experiments.

We repeated this analysis using model output for the period June-December only, rather than the full calen- (a)

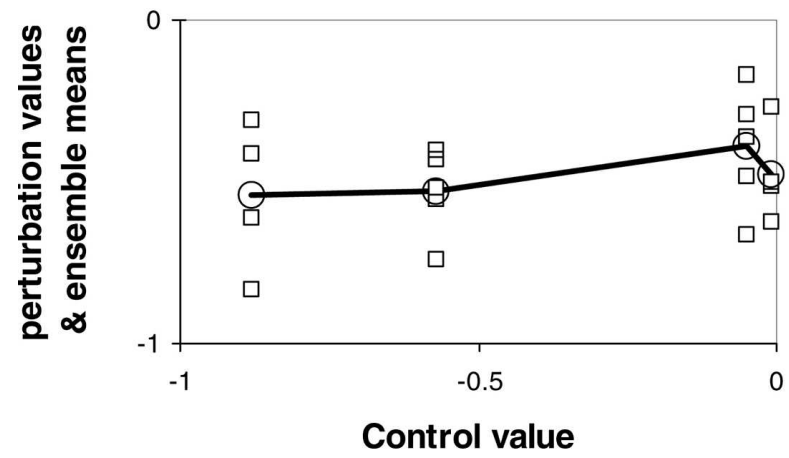

(b)

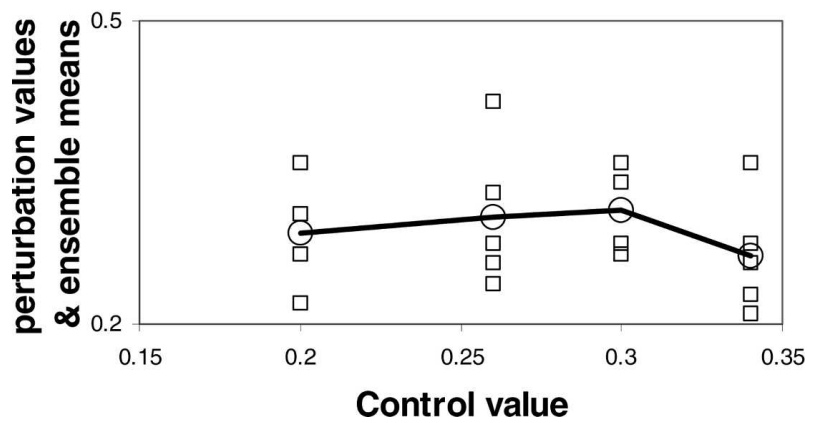

FIG. 4. CGCM: (a) The correlation coefficients between Niño-4 and all-Australia rainfall in the perturbation experiments plotted against the corresponding control values and (b) the standard deviation of Niño- 4 in the perturbation experiments plotted against the corresponding control values. The ensemble means are also presented (open circles). The results are based on 13-yr blocks. Four sets of 13-yr-long perturbation runs were conducted. Two of the sets have five members and two have four members only. All are calculated using annual average data.

dar year, and obtained similar results: if there is predictability in these statistics, then it must be at a low level and a larger number of perturbation experiments is required to reveal it.

\section{A nonlinear relationship between ENSO indices and Australian rainfall}

For the time being suppose that the CGCM provides an accurate assessment of predictability in the real world and that the predictability of interdecadal changes in ENSO's impact on Australia is low or absent. If the interdecadal variations are not predictable, then how can we account for the observational result that the phase of the IPO appears to be statistically linked to the interdecadal changes in ENSO's impact on Australia? It could merely be a statistical fluke of course, though Power et al. (1999a) showed that this is unlikely. 
A more plausible answer to this question lies with a nonlinear relationship between ENSO and Australian rainfall that is evident in the observations. The presence of nonlinearity in some ENSO teleconnections has been discussed by Hoerling et al. (1997). One of the causes of nonlinearity is the appreciable longitudinal shift in the main heating anomaly between La Niña and El Niño events (Hoerling et al. 1997). This difference in the position of atmospheric forcing has the potential to lead to contrasts in teleconnection patterns between $\mathrm{La}$ Niña and El Niño events. An additional reason for nonlinearity in some rainfall teleconnections might be that atmospheric circulation anomalies that lead to rainfall declines cannot reduce rainfall below zero. So at some point the rainfall response in some locations will be capped and so further intensification of the relevant ENSO atmospheric circulation teleconnection will not lead to any further decline in rainfall. In contrast, ENSO-driven atmospheric circulation anomalies that increase rainfall during the opposite phase are not bounded in this way: further intensification of the atmospheric circulation anomaly will lead to even greater rainfall.

Scatterplots of the observed SOI versus observed allAustralia rainfall $R$ and maximum surface temperature $T_{X}$ are given in Figs. 5a and 5b, respectively.

The curves of best fit are nonlinear. The slopes are larger in magnitude if SOI $>0$, and smaller if SOI $<0$. This means that if the (positive) SOI anomaly associated with a La Niña event is large in magnitude, then there is a strong tendency for the rainfall increase to be large. However, a large (negative) SOI excursion associated with an El Niño event provides a poorer guide to how large the drying over Australia will be. In other words, El Niño is associated with drying, but the magnitude of drying is less clearly linked to the magnitude of the SOI anomaly.

Note that for practical purposes surface temperature is not capped (i.e., surface temperatures over Australia are much greater than absolute zero) and so the reason given above for nonlinearity in rainfall teleconnections would not seem to operate for teleconnections to temperature. It is important to realize, however, that rainfall and surface temperature anomalies over land are tightly connected through cloud-radiation and soil moisture-evaporation linkages (e.g., Power et al. 1998a). So one would expect to see nonlinearity associated with rainfall or soil moisture properties to have a signature in surface temperature teleconnections.

Nonlinearity in the relationship between ENSO and Australian climate variables is also evident in the CGCM. Scatterplots of annual average Niño-4 versus all-Australia rainfall and Niño-4 versus all-Australia $T_{X}$ (a)

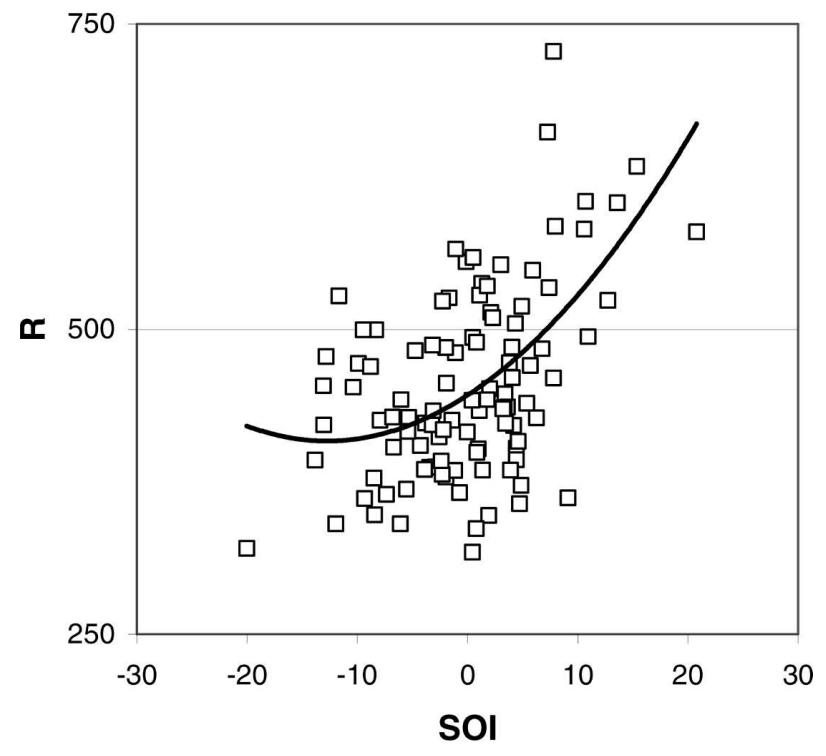

(b)

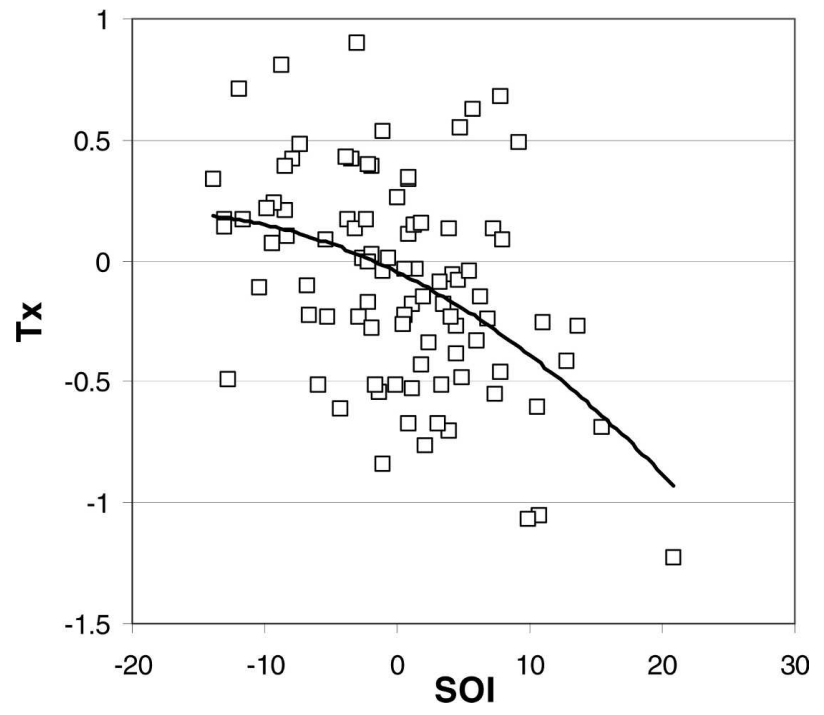

FIG. 5. Observations: Scatterplots of (a) all-Australia rainfall $\left(\mathrm{mm} \mathrm{yr}^{-1}\right)$ vs the SOI for 1900-2004 and (b) all-Australia maximum surface temperature $\left({ }^{\circ} \mathrm{C}\right)$ vs the SOI for 1910-2004. Data are for calendar years. The curve represents the best second-order polynomial fit calculated using the Excel spreadsheet package.

are given in Figs. $6 \mathrm{a}$ and 6b, respectively. The nonlinearity in the first of these is very weak; however, the nonlinear relationship is much stronger between Niño-4 and temperature. Note also that the nonlinearity between rainfall and Niño-4 is much stronger during June-December (Fig. 6c), when ENSO has its greatest impact on Australia.

This nonlinear behavior has a very interesting con- 
(a)

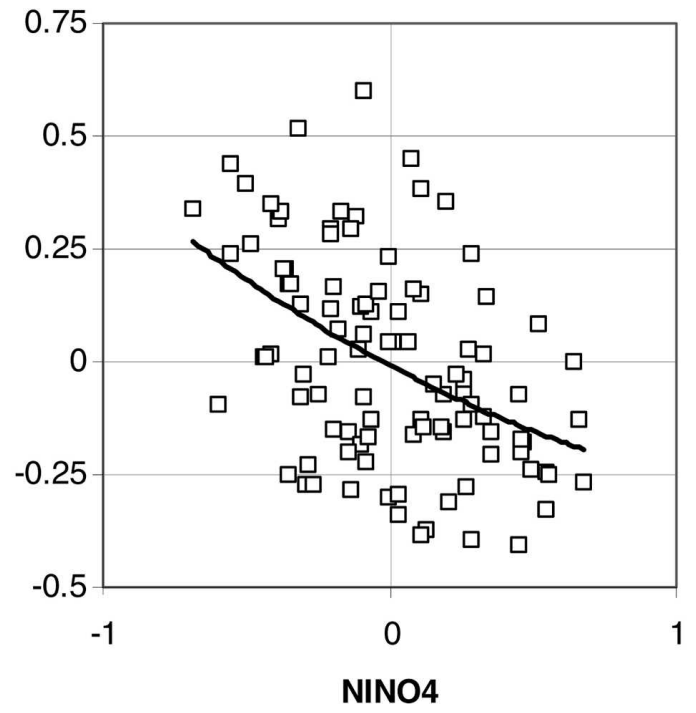

(c)

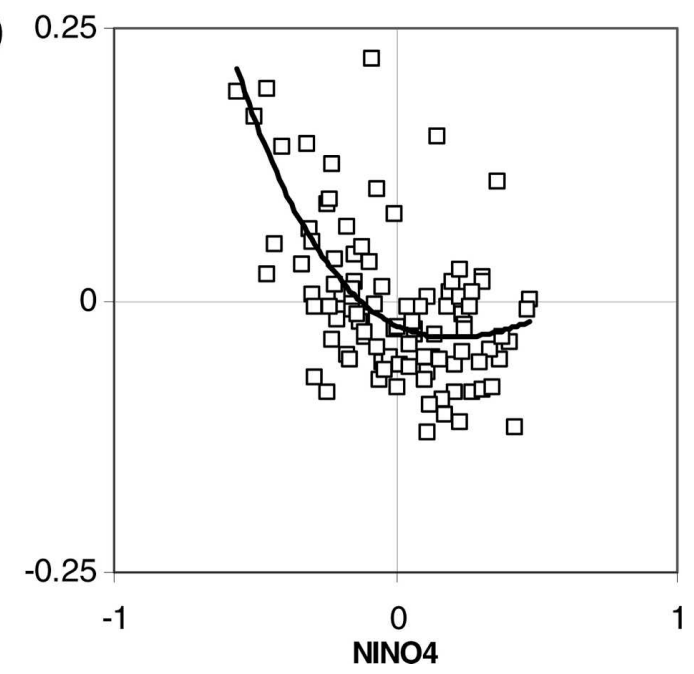

(b)

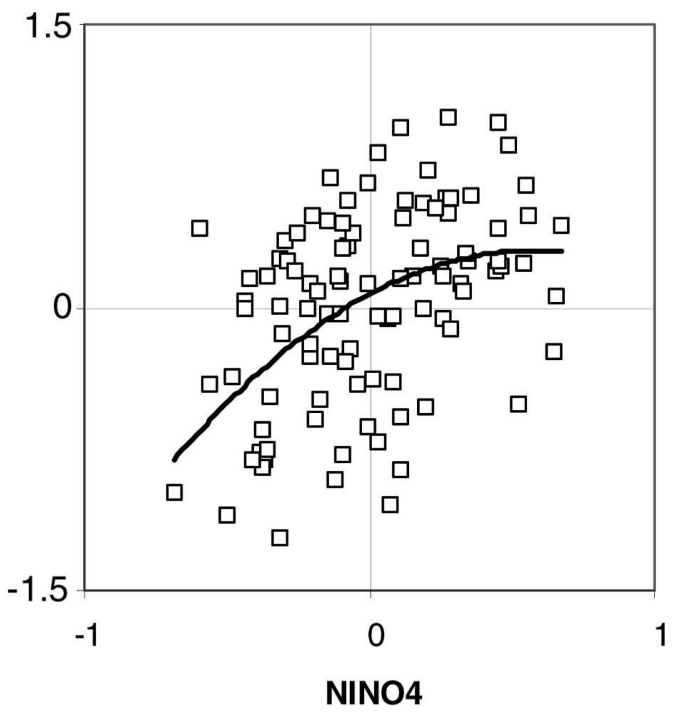

FIG. 6. CGCM: Scatterplots of (a) both all-Australia rainfall vs Niño-4, (b) all-Australia $T_{X}$ vs Niño-4, and (c) allAustralia rainfall vs Niño-4 (June-December only); (a) and (b) are for calendar years.

sequence. If the climate system spends more time during a given interdecadal period on the Niño-4 $<0$ side of phase space (e.g., if the period is dominated by $\mathrm{La}$ Niñas), then the relationship between ENSO and Australian rainfall will seem strong. At the same time, the interdecadal SST anomaly will be La Niña-like simply because the period is more heavily influenced by $\mathrm{La}$ Niña events. The IPO and its index will reflect this dominance of La Niña SST anomalies during the period and tend to be in a negative "phase." (Recall that the IPO negative phase has a La Niña-like appearance, and the IPO positive phase has an El Niño-like appearance.)

This appears to be the case in the CGCM as illustrated in Fig. 7. Figure 7a shows the frequency distribution of June-December Niño-4 for IPO $<0$ years and for IPO $>0$ years. Niño-4 spends more time on the Niño-4 $<0$ side of phase space than the Niño- $4>0$ side when the IPO $<0$. Whereas, Niño-4 spends more time

on the Niño- $4>0$ side in IPO $>0$ years. Since the relationship between Niño-4 and rainfall is stronger in Niño-4 $<0$ years (Fig. 6c), IPO $<0$ years are more heavily influenced by years in which the relationship is strong (Fig. 7b).

The same is true in the observations (Fig. 8). The frequency distribution of the SOI is shifted according to the value of the IPO index (Fig. 8a). The mean SOI for the positive IPO phase is -1.4 compared with 1.4 for the negative phase. The shift is particularly noticeable in the extremes: there are no years when the average SOI is less than -10 for negative IPO years compared with $16 \%$ of years for positive IPO years. Similarly, there are no years when the average SOI is greater than 10 for positive IPO years compared with $19 \%$ of years for negative IPO years. Kiem et al. (2003) also noted that the frequency of La Niña events is increased in the negative IPO phase. Similar results to those in Fig. 8a 

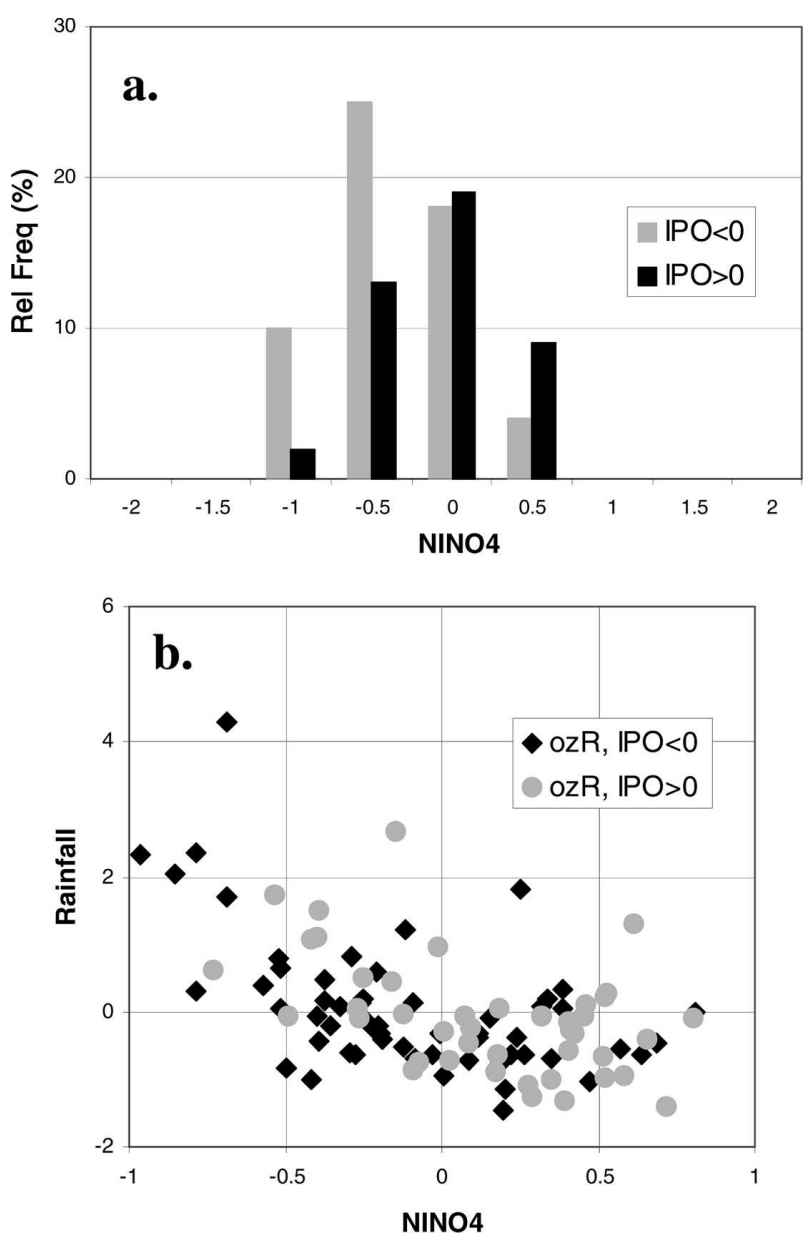

FIG. 7. CGCM: (a) Relative frequency of June-December (JJASOND) Niño-4 for years when the IPO $<0$ (gray rods) and when the IPO $>0$ (black rods), (b) scatterplot of JJASOND Niño-4 and all-Australian rainfall for the IPO $>0$ (gray circles), and the IPO $<0$ (black diamonds).

are shown by Barnett et al. (1999) in a CGCM experiment where the probability distribution of Niño-3 SST anomalies is significantly different depending on the sign of the decadal SST pattern in the North Pacific.

This shift in the frequency histogram of the observed SOI for IPO phases introduces a strong bias in the SOI of years when grouped by the IPO. This is illustrated in Fig. 8b, which shows a scatterplot of annual allAustralia rainfall with the SOI for both IPO $<0$ and IPO $>0$ years. Power et al. (1999a) noted that the correlation between all-Australia rainfall and the SOI was much higher in years when the IPO was negative (0.73) than when the IPO was positive (0.27). This suggests that a large part of this difference is due to the changing nature of the rainfall-SOI relationship depending on the sign of the SOI. If the years are grouped only according to the sign of the SOI, the correlation
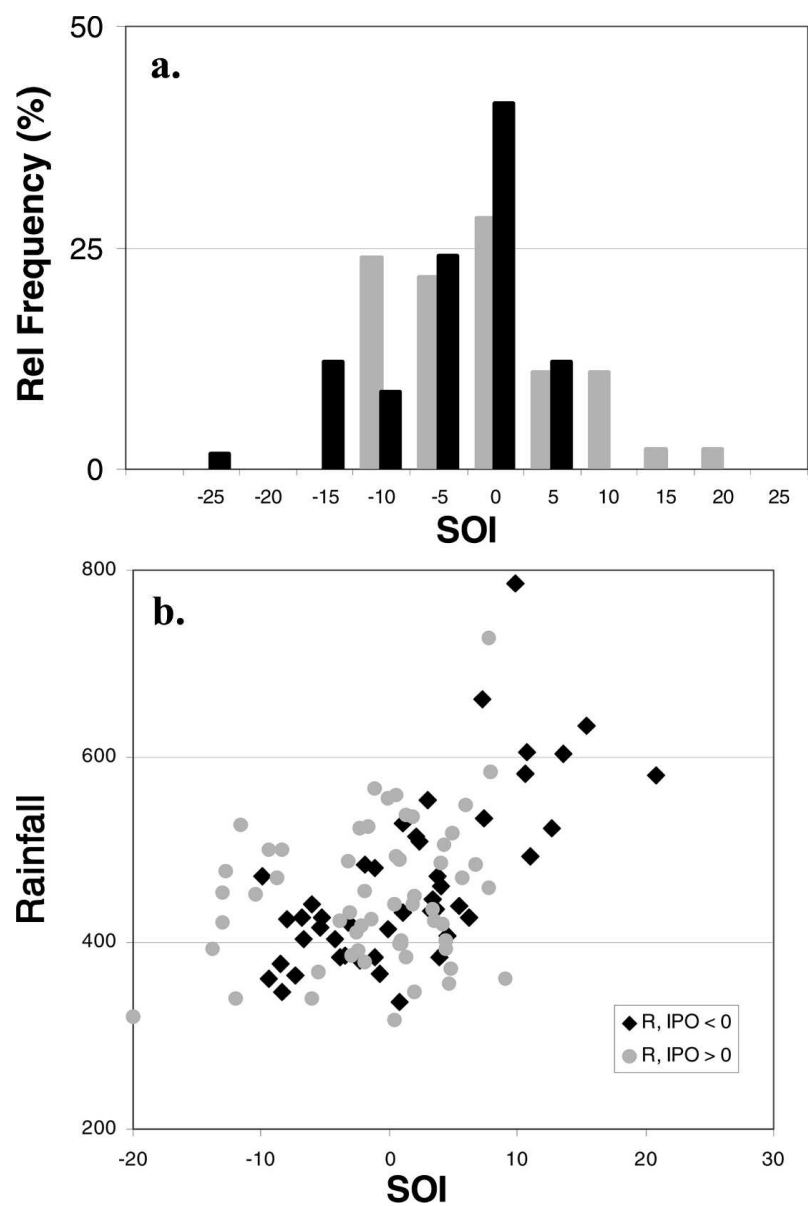

FIG. 8. Observations: (a) Histogram of SOI 1900-97 segregated by phase of IPO (gray rods: IPO $<0$, black rods: IPO $>0$ ) and (b) scatterplot of SOI and Australian rainfall 1900-97 for the IPO > 0 (gray circles) and the IPO $<0$ (black diamonds).

between rainfall and the SOI is 0.58 for positive SOI years and 0.25 for negative SOI years.

We will therefore adopt the working hypothesis that the apparent relationship between the IPO index and the impact that ENSO has on Australia does not reflect a substantial amount of predictability on interdecadal time scales. Instead it arises, in part, through the nonlinear relationship discussed above.

To test this idea further we conducted a simple numerical experiment. In this experiment we simulated two variables, $E(t)$ and $R(t)$, where $t$ is the time in years, $E$ is a normalized measure of ENSO variability (Niño-4 say), and $R$ is the rainfall. Here, $R$ is assumed to be partially, but not totally, dependent on $E$. In this very simple experiment $E$ is assumed to be Gaussian white noise with zero mean. Note that $R$ has two forms depending on the sign of $E$ : if $E \geq 0$, then $R=(1-\varepsilon)$ $E+M$, whereas if $E<0$, then $R=E+M$. Here, $0 \leq$ $\varepsilon<1$ measures the degree to which the relationship is 
nonlinear. If $\varepsilon=0$, the relationship is linear. Here, $M$ is an additional source of white noise. This is of course an approximation to reality. Not all ENSO variables are perfectly Gaussian (see, e.g., Wu et al. 2002), and some may exhibit predictability beyond 1 yr. This simple framework nevertheless serves to address our key question (i.e., can the nonlinearity enhance the decadal modulation of correlations between variables that have zero predictability?) in a straightforward fashion.

Both $E$ and $R$ were simulated for 200 centuries. We then calculated 11-yr overlapping running means of $E$. We will call this running mean the "IPOI" since it is a proxy for the IPO index under our working hypothesis. In this simple model the IPOI tends to be positive in a given 11-yr period if the period is dominated by $\mathrm{El}$ Niños (IPOI >0).

We then collected the simulated coordinates $[E(t)$, $R(t)$ ] and placed them in one of two bins. The first bin, $\mathrm{N}$, has IPOI $<-$ IPOI $_{\text {CRIT }}$ and the second bin, P, has IPOI $>$ IPOI $_{\text {CRIT }}$, where IPO $_{\text {CRIT }}$ is a positive number $(0.8)$. [The use of a nonzero threshold is not crucial, but it does mirror the method used by Power et al. (1999a). They introduced this threshold to even up the size of the bins.] The correlation coefficient between $E$ and $R$ is then calculated for the data in both bins, so we get two correlation coefficients: one for the "IPO positive phase" and one for the "IPO negative phase."

This procedure was repeated for five different values of $\varepsilon=0,0.25,0.5,0.75$, and 1.0 . The results are presented in Fig. 9. The figure shows that when $\varepsilon$ is small and the relationship is linear or weakly nonlinear, the correlation coefficients between $E$ and $R$ in the two bins are the same $(\varepsilon=0)$ or similar $(\varepsilon$ small but $>0)$. However, as the relationship becomes more nonlinear (as $\varepsilon$ gets larger), the correlation coefficients in the two bins differ more markedly. The impact that ENSO seems to have on rainfall $(R)$ in this simple model appears to be greater during periods when the lowfrequency part of $E$ (i.e., the IPOI) is negative (represented by bin $\mathrm{N}$ ).

This supports our working hypothesis that the observed relationship between the IPOI and ENSO's impact on Australia can be obtained, at least in a qualitative sense, without the need for any predictability on interdecadal time scales.

Power et al. (1999a) also noted a statistical association between the IPO index and the vigor of ENSO. They found that the variance of the year-to-year changes in the SOI during the negative phase of the IPO was over twice as large as that during periods when the IPO was positive. Power et al. (1999a) examined a number of variables in their study (rainfall, surface temperature, river flow, crop yield) and they restricted

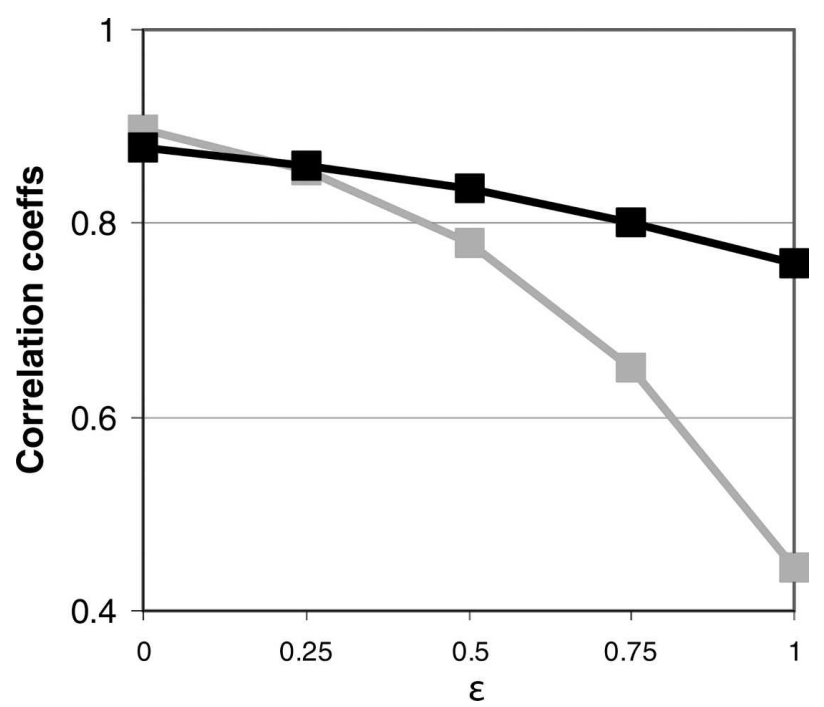

FIG. 9. A simple numerical experiment. The correlation coefficient between simulated rainfall $(R)$ and ENSO index $(E)$ annual data for two cases: $E_{\mathrm{LF}}>0.8\left(\right.$ bin P) and $E_{\mathrm{LF}}<-0.8($ bin N). Here, $E_{\mathrm{LF}}$ is the low-frequency (decadal) component of $E$. In this highly idealized experiment, $R=(1-\varepsilon) E+M$ if $E \geq 0$, whereas $R=E+M$ if $E<0$. Here, $0 \leq \varepsilon<1$ measures the degree to which the relationship between $E$ and $R$ is nonlinear. If $\varepsilon=0$, the relationship is linear. Both $E$ and $M$ are modeled as white noise processes (zero mean, unit standard deviation) and $\alpha$ sets the degree to which $R$ depends on $E$. Here, both $E$ and $R$ are simulated for 200 centuries. The 11-yr running means of $E\left(E_{\mathrm{LF}}\right)$ were then calculated. The simulated coordinates $[E(t), R(t)]$ are placed into one of two bins. The first bin, $N$, has $E_{\mathrm{LF}}<-0.8$ and the second bin, $P$, has $E_{\mathrm{LF}}>0.8$. The correlation coefficients between all of the coordinates in each bin are depicted for each value of $\varepsilon$.

their attention to the period for which they had data for all the variables they considered, namely, 1910-90. However, if we repeat this analysis on the longer period 1876-2001, then there is virtually no difference in the variance of the SOI in the IPOI positive and negative bins. This particular result of Power et al. (1999a) might therefore be due to sampling error (or perhaps, as a reviewer suggests, variability on even longer time scales).

Here we have restricted attention to interdecadal changes in ENSO's impact on Australian rainfall. Of course ENSO affects other variables in many other parts of the world and not all of the relationships between ENSO indices and a variable of interest (e.g., rainfall in a particular region) will exhibit the same kind of nonlinearity discussed above. While some relationships will be nonlinear (Hoerling et al. 1997), in many cases a particular relationship might well be linear. However, this does not change the fact that the IPO or PDO can still seem to modulate ENSO's impact on that variable but in a different way. To understand how, consider the example in which the variable of interest tends to increase linearly as Niño-4 increases. In this 
case the IPO is again the low-frequency component of Niño-4 variability in our simple stochastic model. The Niño-4 variability comprises this low-frequency part and a higher-frequency, interannual part. In a given year Niño-4 will be largest when the IPOI and the yearto-year variability both have a positive value. So the IPO will appear to make El Niño impacts stronger when the IPO is positive. Similarly, El Niño impacts will appear to be weakened and La Niña impacts stronger when the IPO is negative. This more straightforward linear superposition might help to explain part of the shifts in the position of the South Pacific convergence zone (SPCZ) described by Folland et al. (2002). They found that ENSO and the IPO shifted the SPCZ NE-SW in a similar fashion. During El Niño and positive phases of the IPO - that is, when the central eastern Pacific is anomalously warm-the SPCZ shifts NE. During La Niña events and negative phases of the IPO- that is, when the central eastern Pacific is anomalously cool-the SPCZ shifts SW. Again, interdecadal predictability is not necessarily needed to explain these results, if the IPO is regarded as simply marking random interdecadal changes in ENSO activity.

So an apparent modulation of ENSO's impacts on the given variability of interest does not rely on nonlinearity. Instead, the nonlinearity can influence the statistical nature of the apparent modulation if the nonlinear effect is large enough-as it is in the Australian context discussed above.

Of course different types of nonlinearities can lead to different apparent forms of modulation. Furthermore, we can also expect the character of the statistical relationship between a given ENSO index and a given variable to vary spatially. This helps to account for spatial contrasts in the way the IPO appears to influence ENSO teleconnections in different parts of the world (e.g., as described by Salinger et al. 2001).

\section{The nature of the IPO-PDO}

In the paradigm underpinning the simple numerical experiments above, the IPO and PDO indices merely reflect unpredictable low-frequency changes in ENSO variability. But is this true? If the observed IPO index was merely reflecting low-frequency changes in ENSO variability, then you would expect there to be a strong relationship between the low-frequency (LF) parts of both the SOI and Niño-3.4, say, with the IPO index. These three time series are shown in Fig. 10. The sign of the SOI has been reversed so the interrelationships can be seen more easily. The correlation coefficients are -0.57 between the LF SOI and the IPOI, and 0.65 between the LF Niño-3.4 and IPOI. What is really strik-

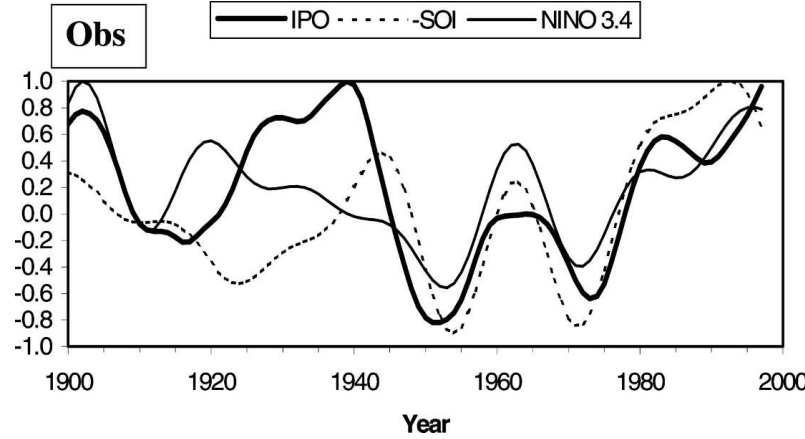

FIG. 10. Observed value of the IPO index and the low-frequency component of the SOI and Niño-3.4 for 1900-97. The low-pass filter used is a spectral filter with a 13-yr cutoff. All of the time series have been standardized so they have unit variance. The sign of the SOI has been reversed.

ing in the plot is the similarity between the three indices in the latter part of the record when the SST data are more reliable. In fact, for the period 1945-97 the correlation coefficients between the IPO and the low-passfiltered SOI and Niño-3.4 indices are -0.91 and 0.91 , respectively. This might merely be fortuitous. On the other hand, it might reflect a reduction in observational error in the modern period (J. Leloup 2003, personal communication).

To examine the relationship between the CGCM's ENSO and its IPO, we performed an EOF analysis of the CGCM Indo-Pacific SSTs. Recall that the term IPO is used to describe the El Niño-like EOF of low-passfiltered near-global SST as calculated by Folland et al. (1999). We applied a low-pass filter with a 13-yr cutoff to the CGCM's SST and then calculated the EOFs. The first EOF of low-pass-filtered SST is El Niño-like (Fig. 11a). This is the model's representation of the IPO. The time series of the model IPO is shown in Fig. 11b.

We then low-pass filtered the time series of the first EOF of unfiltered data (the CGCM's SST El Niño pattern presented in Fig. 1) and the resulting time series is also presented in the same figure (Fig. 11b). The two time series are strikingly similar. The correlation coefficient between them is 0.97 . So indices for the IPO (or the interdecadal part of the PDO) very closely reflect low-frequency changes in ENSO. This is consistent with observations if we take observational error in the earlier part of the observational record into account.

Whether or not the relationship in the real world is as strong as it is in the model, we can safely assume that indices of the IPO (and PDO) provide proxy records for the interdecadal variability in ENSO indices. The question "how predictable are indices of the IPO or PDO?" can therefore be re-posed as "how predictable are the decadal components of ENSO indices?" 
(a)
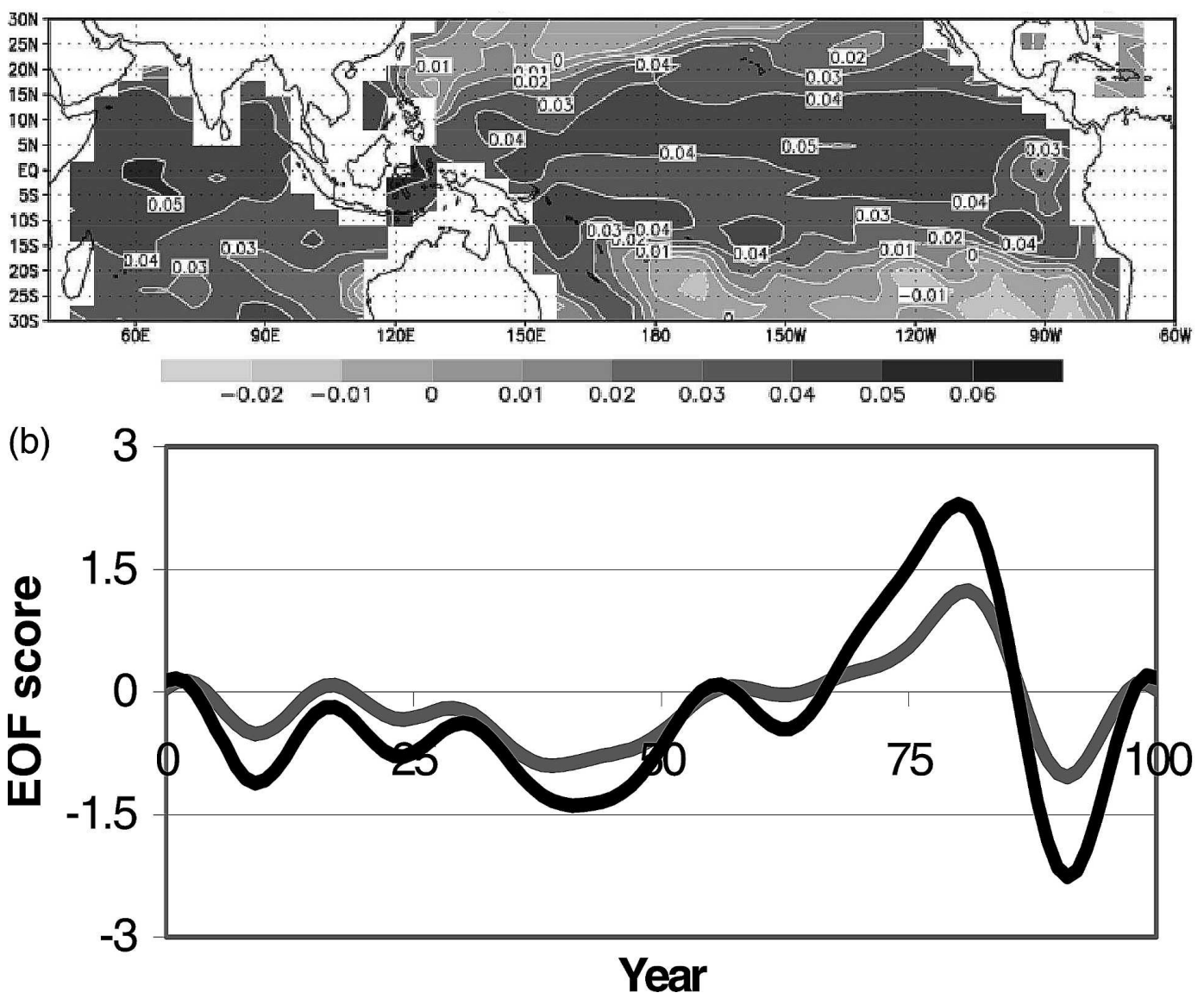

FIG. 11. CGCM: The first EOF of low-pass-filtered SST: (a) the spatial structure and (b) its time series. The low-pass-filtered time series of the first EOF of unfiltered SST is also shown in (b). A spectral filter with a 13-yr cutoff was used.

\section{Modulation of ENSO teleconnections in the CGCM}

As noted in the introduction, the IPO index was coherent with interdecadal changes in the relationship between ENSO and year-to-year changes in Australian climate during the twentieth century. To see if this is also the case in the CGCM we examined the relationship between the model's IPO index and interdecadal variability in the correlation coefficient between Niño-4 and $R$. The correlation coefficients are -0.016 and +0.56 for annual and June-December data, respectively. So the modulation is not present in the CGCM for annual data. The second correlation coefficient has a sign that is consistent with the observations: if the IPO is warm, the magnitude of the correlation coefficient declines. The coefficient is modest and only accounts for about $30 \%$ of the total variability. The association between the IPO and ENSO rainfall teleconnections during June-December is also depicted in Fig. 12. It shows the distribution of correlation coefficients between Niño-4 and all-Australia rainfall in the CGCM using 13-yr blocks. Two relative frequency plots are shown, one for periods when the IPO index is negative and one for when the IPO index is positive. Notice that the frequency of low-magnitude correlations is increased and the frequency of high-magnitude correlations is reduced when the IPO index $>0$, compared with the case when the IPO index $<0$. This is consistent with the correlation coefficient of +0.56 discussed above. It is also consistent with the observational relationship and the arguments outlined in the previous section.

The absence of modulation in the CGCM for annual data is also consistent with the previous discussion because the nonlinearity of the relationship between annual rainfall and annual Niño-4 in the CGCM is very weak (section 5, Fig. 6a). The fact that this nonlinearity is weaker than it is in the observations lends weight to the caveat that the CGCM might be underestimating real-world predictability. 


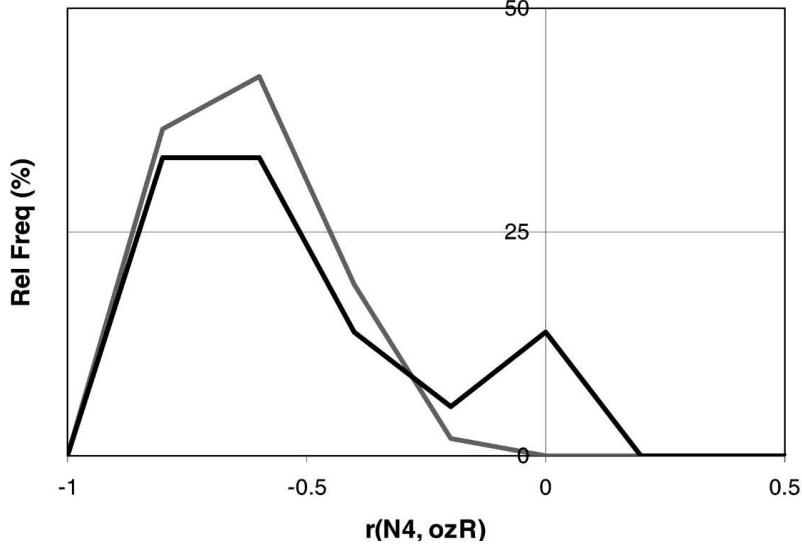

FIG. 12. CGCM: Relative frequency (\%) of correlation coefficients between Niño-4 and all-Australia rainfall (using JuneDecember averages) in 13-yr blocks. One distribution corresponds to the case when the IPO index $>0$ (black) and the other when the IPO index $<0$ (gray). Note how more larger-magnitude correlations occurred when the IPO $<0$.

\section{Summary and discussion}

\section{a. The asymmetric response of Australian climate to ENSO}

El Niño-Southern Oscillation (ENSO) in a centurylong integration of a BMRC coupled general circulation model (CGCM; Power et al. 1998b) that drives rainfall and temperature changes over Australia that are broadly consistent with documented observational changes in that dry/hot conditions occur more frequently during El Niño years and wet/mild conditions occur more frequently during La Niña years. The relationship between ENSO (as measured by Niño-4 or the Southern Oscillation index, SOI, say) and all-Australia rainfall and temperature is found to be nonlinear in the observations (Figs. 5a and 5b) and during JuneDecember in the CGCM (Fig. 6c): a large La Niña sea surface temperature (SST) anomaly (or a large La Niña SOI excursion) is closely linked to a large Australian response (i.e., Australia usually becomes much wetter), whereas the magnitude of an El Niño SST or SOI anomaly is a poorer guide to how dry Australia will actually become. There is no doubt that Australia tends to dry out during El Niño events, but the degree of drying is not as tightly linked to the magnitude of the El Niño SST anomaly. This surprising result has important implications for climate prediction services. Forecasting centers and the media sometimes emphasize the magnitude of El Niño SST anomalies when discussing climate predictions. This is valid in many parts of the world where the response is linear. Our results show, however, that this may be less helpful in the Australian context. This is because a large El Niño SST signal does not increase the risk of severe drought (at least in terms of continental average rainfall) from the risk associated with a more modest El Niño SST anomaly.

\section{b. Decadal variability in ENSO teleconnections and its links to the IPO-PDO}

In some decades the relationship between ENSO and Australian climate (in both the model and the observations, measured using correlation coefficients) is strong, whereas in other decades it is weak. A series of decadal-long perturbation experiments with the CGCM were used to show that if these interdecadal changes are predictable, then the level of predictability is low.

Previous work (Power et al. 1999a) demonstrated that an index for the Interdecadal Pacific Oscillation (IPO), which is an interdecadal El Niño-like SST pattern that is closely related to the interdecadal component of an index for the Pacific Decadal Oscillation (PDO; Mantua et al. 1997), is statistically linked to changes in ENSO's impact on Australian climate during the twentieth century. When the IPO was in a negative phase, the impact of ENSO on Australia was enhanced. A simple nonlinear stochastic model was used to show that, in theory at least, interdecadal excursions in ENSO indices (e.g., a 13-yr running average of Niño4) will tend to be statistically coherent with interdecadal changes in measures of ENSO teleconnections (e.g., the correlation coefficient between Niño-4 and all-Australia rainfall in 13-yr blocks) even in the absence of predictability beyond $1 \mathrm{yr}$. In this simple model the interdecadal component of ENSO variability represents a residual ENSO-like SST pattern arising from random changes in ENSO. For example, a given interdecadal period might have a larger number of El Niño events than La Niña events. Or, if the frequency of the El Niño and La Niña events is then same during a given interdecadal period, then the El Niño events might have been larger in terms of SST anomalies than the SST anomalies associated with the La Niña events that occurred in the same interdecadal period. Of course, this also means that indices that resemble lowfrequency excursions in ENSO indices can also appear to modulate ENSO teleconnections, again without the need for predictability beyond $1 \mathrm{yr}$.

The CGCM's IPO is statistically linked to interdecadal changes in ENSO's impact on Australia during June-December when ENSO's impact on Australia is generally greatest. However, IPO indices in both the model and the observations both approximate interdecadal changes in Niño-4. So even if the IPO or PDO merely reflects random changes in ENSO statistics (e.g., the relative number of El Niño and La Niña events) on interdecadal time scales they can, in the 


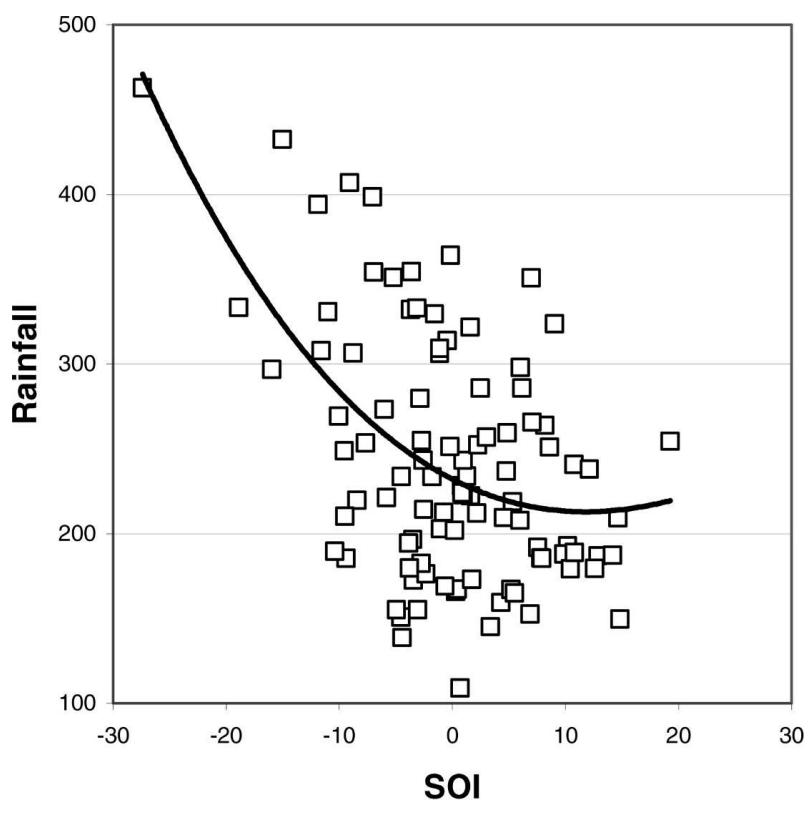

FIG. 13. Observations: The relationship between OctoberMarch precipitation averaged over the southwestern United States and northern Mexico $\left(32.5^{\circ}-37.5^{\circ} \mathrm{N}\right.$ and $\left.235^{\circ}-255^{\circ} \mathrm{E}\right)$ and the SOI for the same time of the year. Data derived from the gridded data for 1900-97 described by New et al. (2001).

presence of nonlinear teleconnections, appear to modulate ENSO teleconnections. Modulation can occur without nonlinearity, but nonlinearity increases the likelihood that modulation will occur.

Note that while nonlinearity is an influential feature in the Australian context, nonlinearity is not necessarily crucial to the appearance of apparent modulation of ENSO teleconnections by the IPO or PDO in all locations. In the linear case El Niño impacts will appear to be enhanced (weakened) during IPO positive (negative) phases and La Niña impacts will appear to be enhanced (weakened) during IPO negative (positive) phases. Furthermore, different nonlinear forms can give rise to different forms of apparent modulation. For example, if the El Niño SST anomalies were more closely linked to variability in a particular region than La Niña SST anomalies, then IPO positive phases will appear to enhance ENSO's impact in that region.

Nonlinear ENSO teleconnections are not restricted to Australia. An important example is given in Fig. 13, which depicts the nonlinear nature of ENSO teleconnections to the southwestern United States and northern Mexico. In this region the magnitudes of La Niña SST anomalies are less clearly linked to the magnitudes of rainfall anomalies than are the El Niño SST anomalies. La Niña SSTs increase the risk of dry conditions, but the degree of drying is not tightly linked to the magnitude of the SST anomaly. So the conclusions drawn above may have relevance here too.

\section{c. Additional implications}

Our results also indicate that even a statistically significant relationship between IPO or PDO indices and interdecadal variability in ENSO's impact on a given quantity linked to surface climate (e.g., rainfall, river flow, crop yield, fire risk) is not necessarily underpinned by any interdecadal predictability. Instead, the statistical association could largely reflect unpredictable changes in the impact that ENSO has on the variable of interest.

Improving our understanding of low-frequency variability in ENSO has the potential to improve our ability to predict climate. However, realizing this potential in the development of new statistical schemes incorporating IPO-PDO indices, for example, will require careful consideration of the underpinning physical mechanisms.

\section{d. Caveats and future work}

In this paper we have shown that interdecadal changes in ENSO activity and ENSO's impact on surface climate (rainfall, land and sea surface temperature) can be explained, at least in a qualitative sense, without the need for predictability on interdecadal time scales. Note that this does not rule out the possibility that a fraction of the interdecadal variability evident in ENSO indices is actually predictable on multiyear time scales and beyond. Note, for example, that observed ENSO indices have probability density functions that tend to be more skewed than their CGCM counterparts (Wu et al. 2002). So perhaps the CGCM is underestimating processes that could underpin greater predictability on decadal time scales. Furthermore, a number of recent studies indicate that some of the interdecadal variability in the Tropics has an extratropical origin (e.g., Barnett et al. 1999; Hazeleger et al. 2001; Liu et al. 2002; Wu et al. 2003; Galanti and Tziperman 2003; Nonaka et al. 2002; Kleeman et al. 1999; Lysne et al. 1997; Lohmann and Latif 2004; White et al. 2003; Meehl and $\mathrm{Hu} 2006$ ) via the atmosphere and ocean. Given that the oceanic teleconnections typically require time delays of $2 \mathrm{yr}$ to over a decade before the extratropical signal is communicated to the equator (e.g., Nonaka et al. 2002; White et al. 2003), they may drive a predictable component in overall IPO activity. While quantification of the level of predictability in the IPO-PDO is the subject of ongoing research, our results suggest that the predictable component is small.

Interdecadal variability in ENSO, whether it is partially predictable or not, must drive changes in the ocean by, for example, changes in wind stresses. Some 
of this variability will therefore drive slow oceanic responses that could be predictable beyond interannual time scales. This may help to explain robust differences between ENSO and decadal ENSO-like patterns that a simple stochastic or residual model cannot. These issues will be discussed elsewhere.

Acknowledgments. SBP thanks Pandora Hope and Guo Liu for their help in compiling the CGCM output; Greg McKeon, Stewart Franks, Holger Meinke, and Barry White for their encouragement and interest in this work over many years; and Aurore Moise for a careful review of an earlier draft. Xiangdong Wang and Pandora were supported by Climate Variability in Agriculture Program (CVAP, administered by Land and Water Australia) funding for this project. Guo is supported by the Australian Climate Change Science Program, which is administered by the Australian Greenhouse Office.

\section{REFERENCES}

AchutaRao, K., and K. R. Sperber, 2002: Simulation of the El Niño-Southern Oscillation: Results from the Coupled Model Intercomparison Project. Climate Dyn., 19, 191-209.

Adams, R., K. Bryant, B. McCarl, D. Legler, J. O'Brien, A. Solow, and R. Weiher, 1995: Value of improved long-range weather information. Contemp. Econ. Policy, 13 (3), 10-19.

Allan, R. J., 1991: Australasia. Teleconnections Linking Worldwide Climate Anomalies, M. H. Glantz, R. W. Katz, and N. Nicholls, Eds., Cambridge Academic Press, 73-120.

_- J. Lindesay, and D. Parker, 1996: El Niño Southern Oscillation and Climatic Variability. CSIRO Publishing, 402 pp.

Arblaster, J. M., G. A. Meehl, and A. M. Moore, 2002: Interdecadal modulation of Australian rainfall. Climate Dyn., 18, 519531 .

Barnett, T. P., D. W. Pierce, R. Saravanan, N. Schneider, D. Dommenget, and M. Latif, 1999: Origins of midlatitude Pacific decadal variability. Geophys. Res. Lett., 26, 1453-1456.

Battisti, D. S., and A. C. Hirst, 1989: Interannual variability in the tropical atmosphere-ocean system: Influence of the basic state, ocean geometry, and nonlinearity. J. Atmos. Sci., 46, 1687-1712.

Bettio, L., S. Power, and K. Walsh, 2003: The dynamics of ENSO in a coupled GCM. Abstracts, Int. Conf. on Earth System Modelling, Hamburg, Germany, Max Planck Institute for Meteorology, p. 138.

Blanke, B., J. D. Neelin, and D. Gutzler, 1987: Estimating the effect of stochastic wind stress forcing on ENSO irregularity. J. Climate, 10, 1473-1486.

Bryan, K., 1969: A numerical method for the study of the circulation of the world ocean. J. Comput. Phys., 4, 347-376.

Burgers, G., 1999: The El Nino stochastic oscillator. Climate Dyn., 15, 521-531.

Cane, M. A., M. Münnich, and S. E. Zebiak, 1990: A study of self-excited oscillations of the tropical ocean-atmosphere system. Part I: Linear analysis. J. Atmos. Sci., 47, 1562-1577.

Chen, D., L. M. Rothstein, and A. J. Busalacchi, 1994: A hybrid vertical mixing scheme and its application to tropical ocean models. J. Phys. Oceanogr., 24, 2156-2179.
Chu, P.-S., and R. W. Katz, 1985: Modeling and forecasting the Southern Oscillation: A time-domain approach. Mon. Wea. Rev., 113, 1876-1888.

Colman, R. A., 2001: On the vertical extent of atmospheric feedbacks. Climate Dyn., 17, 391-405.

- B. McAvaney, J. Fraser, and R. Dahni, 1992: Mixed layer ocean and thermodynamic sea-ice models in the BMRC GCM. BMRC Research Rep. 30, 35 pp.

_, J. Fraser, and L. Rotstayn, 2001: Climate feedbacks in a general circulation model incorporating prognostic clouds. Climate Dyn., 18, 103-122.

Davey, M., and Coauthors, 2002: STOIC: A study of coupled model climatology and variability in tropical ocean regions. Climate Dyn., 18, 403-420.

Della-Marta, P., D. Collins, and K. Braganza, 2004: Updating Australia's high-quality annual temperature dataset. Aust. Meteor. Mag., 53, 75-93.

Dijkstra, H. A., and G. Burgers, 2002: Fluid dynamics of El Niño variability. Annu. Rev. Fluid Mech., 34, 531-558.

Folland, C. K., D. E. Parker, A. W. Colman, and R. Washington, 1999: Large scale modes of ocean surface temperature since the late nineteenth century. Beyond El Niño: Decadal and Interdecadal Climate Variability, A. Navarra, Ed., SpringerVerlag, 73-102.

_ J. A. Renwick, M. J. Salinger, and A. B. Mullan, 2002: Relative influences of the Interdecadal Pacific Oscillation and ENSO on the South Pacific convergence zone. Geophys. Res. Lett., 29, 1643, doi:10.1029/2001GL014201.

Frankignoul, C., and K. Hasselmann, 1977: Stochastic climate models. Part II: Application to sea-surface temperatures and thermocline variability. Tellus, 29, 284-305.

— , P. Muller, and E. Zorita, 1997: A simple model of the decadal response of the ocean to stochastic wind forcing. J. Phys. Oceanogr., 27, 1533-1546.

Galanti, E., and E. Tziperman, 2003: A midlatitude-ENSO teleconnection mechanism via baroclinically unstable long Rossby waves. J. Phys. Oceanogr., 33, 1877-1888.

Gates, W. L., and A. B. Nelson, 1975: A new (revised) tabulation of the Scripps topography on a $1^{\circ}$ global grid. Part I: Terrain heights. RAND Corporation Tech. Rep. R-1276-1-ARPA, $132 \mathrm{pp}$.

Gershunov, A., and T. P. Barnett, 1998: Interdecadal modulation of ENSO teleconnections. Bull. Amer. Meteor. Soc., 79, 27152725.

Gill, A. E., 1982: Atmosphere-Ocean Dynamics. Academic Press, $662 \mathrm{pp}$.

Halpert, M. S., and C. F. Ropelewski, 1992: Surface temperature patterns associated with the Southern Oscillation. J. Climate, $\mathbf{5}, 577-593$

Hasegawa, T., and K. Hanawa, 2003: Decadal-scale variability of upper ocean heat content in the tropical Pacific. Geophys. Res. Lett., 30, 1272, doi:10.1029/2002GL016843.

Hazeleger, W., M. Visbeck, M. Cane, A. Karspeck, and N. Naik, 2001: Decadal upper ocean temperature variability in the tropical Pacific. J. Geophys. Res., 106, 8971-8988.

Hoerling, M. P., A. Kumar, and M. Zhang, 1997: El Niño, La Niña, and the nonlinearity of their teleconnections. J. Climate, 10, 1769-1786.

Houghton, J. T., Y. Ding, D. J. Griggs, M. Noguer, P. J. van der Linden, X. Dai, K. Maskell, and C. A. Johnson, Eds., 2001: Climate Change 2001: The Scientific Basis. Cambridge University Press, $881 \mathrm{pp}$.

Hunt, B. G., and T. I. Elliott, 2003: Secular variability of ENSO 
events in a 1000-year climatic simulation. Climate Dyn., 20, 689-703.

James, I. N., and P. M. James, 1992: Ultra low frequency variability of the flow in a simple atmospheric model. Quart. J. Roy. Meteor. Soc., 118, 1211-1233.

Jin, F.-F., 1997: An equatorial recharge paradigm for ENSO. Part I: Conceptual model. J. Atmos. Sci., 54, 811-829.

_ D. Deelin, and M. Ghil, 1994: ENSO on the devil's staircase: Annual subharmonic steps to chaos. Science, 264, 70-72.

Jones, D. A., 1999: Characteristics of Australian land surface temperature variability. Theor. Appl. Climatol., 63, 11-31.

_- and G. Weymouth, 1997: An Australian monthly rainfall dataset. Bureau of Meteorology Tech. Rep. 70, Melbourne, Australia, $19 \mathrm{pp}$.

Kestin, T. S., D. J. Karoly, J.-I. Yano, and N. A. Rayner, 1998: Time-frequency variability of ENSO and stochastic simulations. J. Climate, 11, 2258-2272.

Kiem, A. S., and S. W. Franks, 2004: Multidecadal variability of drought risk, eastern Australia. Hydrol. Processes, 18, 20392050.

— - — , and G. Kuczera, 2003: Multi-decadal variability of flood risk. Geophys. Res. Lett., 30, 1035, doi:10.1029/ 2002GL015992.

Killworth, P. D., 1987: Topographic instabilities in level model OGCM's. Ocean Modell., 75 (unpublished manuscript), 9-12.

Kleeman, R., and S. B. Power, 1994: Limits to predictability in a coupled ocean-atmosphere model due to atmospheric noise. Tellus, 46A, 529-540.

—, and —-, 2000: Modulation of ENSO variability on decadal and longer timescales. El Niño and the Southern Oscillation: Multiscale Variability and Global and Regional Impacts, H. F. Diaz and V. Markgraf, Eds., Cambridge University Press, 413-442.

— J. P. McCreary, and B. A. Klinger, 1999: A mechanism for generating ENSO decadal variability. Geophys. Res. Lett., 26, 1743-1746.

Koch, S. E., M. Des Jardins, and P. J. Kochin, 1983: An interactive Barnes objective map analysis scheme for use with satellite and conventional data. J. Climate Appl. Meteor., 22, 14871503.

Knutson, T. R., and S. Manabe, 1998: Model assessment of decadal variability and trends in the tropical Pacific Ocean. $J$. Climate, 11, 2273-2296.

Lacis, A. A., and J. E. Hansen, 1974: A parameterization for the absorption of solar radiation in the earth's atmosphere. $J$. Atmos. Sci., 31, 118-133.

Latif, M., and T. P. Barnett, 1994: Causes of decadal climate variability over the North Pacific and North America. Science, 266, 634-637.

— tercomparison Project. Climate Dyn., 18, 255-276.

Liu, Z., L. Wu, R. Gallimore, and R. Jacob, 2002: Search for the origins of Pacific decadal climate variability. Geophys. Res. Lett., 29, 1404, doi:10.1029/2001GL013735.

Lohmann, K., and M. Latif, 2005: Tropical Pacific decadal variability and the subtropical-tropical cells. J. Climate, 18, 51635178.

Louis, J.-F., 1983: Parameterization of sub-grid scale processes. Proc. ECMWF Seminar on the Interpretation of NWP Products, Reading, United Kingdom, ECMWF, 83-96.

Lysne, J., P. Chang, and B. Giese, 1997: Impact of the extratropical Pacific on equatorial variability. Geophys. Res. Lett., 24, 2589-2592.
Manabe, S., and J. L. Holloway, 1975: The seasonal variation of the hydrological cycle as simulated by a global model of the atmosphere. J. Geophys. Res., 80, 1617-1649.

Mann, M. E., R. S. Bradley, and M. K. Hughes, 2000: Long-term variability in the El Niño/Southern Oscillation and associated teleconnections. El Niño and the Southern Oscillation: Multiscale Variability and Global and Regional Impacts, H. F. Diaz and V. Markgraf, Eds., Cambridge University Press, 357-412.

Mantua, N. J., S. R. Hare, Y. Zhang, J. M. Wallace, and R. C. Francis, 1997: A Pacific interdecadal climate oscillation with impacts on salmon production. Bull. Amer. Meteor. Soc., 78, 1069-1079.

McAvaney, B. J., and G. D. Hess, 1996: The revised surface fluxes parameterization in BMRC formulation. BMRC Research Rep. 56, 27 pp.

McCabe, G. J., and M. D. Dettinger, 1999: Decadal variations in the strength of ENSO teleconnections with precipitation in the western U.S. Int. J. Climatol., 19, 1399-1410.

McKeon, G. M., and Coauthors, 2004a: Historical degradation episodes in Australia: Global climate and economic forces and their interaction with rangeland grazing systems. Pasture Degradation and Recovery in Australia's Rangelands: Learning from History, G. McKeon et al., Eds., Natural Resource Sciences, Queensland Department of Natural Resources and Mines, Queensland, Australia, 27-86.

, I. W. Watson, W. B. Hall, B. K. Henry, S. B. Power, and G. S. Stone, 2004b: Summary. Pasture Degradation and Recovery in Australia's Rangelands: Learning from History, G. McKeon et al., Eds., Natural Resource Sciences, QNRM, Queensland, Australia, 17-26.

Meehl, G. A., and A. Hu, 2006: Megadroughts in the Indian monsoon region and southwest North America and a mechanism for associated multidecadal Pacific sea surface temperature anomalies. J. Climate, 19, 1605-1623.

Miller, A. J., and N. Schneider, 2000: Interdecadal climate regime dynamics in the North Pacific Ocean: Theories, observations and ecosystem impacts. Progress in Oceaonography, Vol. 47, Pergamon, 355-379.

- and Coauthors, 2003: Potential feedbacks between Pacific Ocean ecosystems and interdecadal climate variations. Bull. Amer. Meteor. Soc., 84, 617-633.

Miller, M. J., A. C. M. Beljaars, and T. N. Palmer, 1992: The sensitivity of the ECMWF model to the parameterization of evaporation from the tropical ocean. J. Climate, 5, 418-434.

Moore, A. M., and R. Kleeman, 1999: Stochastic forcing of ENSO by the intraseasonal oscillation. J. Climate, 12, 1199-1220.

Münnich, M., M. A. Cane, and S. E. Zebiak, 1991: A study of self-excited oscillations of the tropical ocean-atmosphere system. Part II: Nonlinear cases. J. Atmos. Sci., 48, 1238-1248.

Neelin, J. D., D. S. Battisti, A. C. Hirst, F.-F. Jin, Y. Wakata, T. Yamagata, and S. E. Zebiak, 1998: ENSO theory. J. Geophys. Res., 103, 14 261-14 289.

New, M., M. Todd, M. Hulme, and P. Jones, 2001: Precipitation measurements and trends in the twentieth century. Int. J. Climatol., 21, 1899-1922.

Nicholls, N., 1992: Historical El Niño/Southern Oscillation variability in the Australian region. El Nino, Historical and Paleoclimatic Aspects of the Southern Oscillation, H. F. Diaz and V. Markgraf, Eds., Cambridge Academic Press, 151-174.

, B. Lavery, C. Frederiksen, W. Drosdowsky, and S. Torok, 1996: Recent changes in relationships between the El Niño- 
Southern Oscillation and Australian rainfall and temperature. Geophys. Res. Lett., 23, 3357-3360.

Nonaka, M., S.-P. Xie, and J. P. McCreary, 2002: Decadal variations in the subtropical cells and equatorial Pacific SST. Geophys. Res. Lett., 29, 1116, doi:10.1029/2001GL013717.

Pacanowski, R. C., K. Dixon, and A. Rosati, 1991: The GFDL Modular Ocean Model user's guide, version 1.0. GFDL Ocean Group Tech. Rep. 2, 376 pp.

Palmer, T. N., G. J. Shutts, and R. Swinbank, 1986: Alleviation of a systematic bias in general circulation and numerical weather prediction models through an orographic gravity wave drag parameterization. Quart. J. Roy. Meteor. Soc., 112, 1001-1039.

Penland, C., and P. D. Sardeshmukh, 1995: The optimal growth of tropical sea surface temperature anomalies. J. Climate, 8 , 1999-2024.

Philander, S. G., 1990: El Niño, La Niña, and the Southern Oscillation. International Geophysical Series, Vol. 46, Academic Press, 293 pp.

Pierce, D. W., 2002: The role of sea surface temperatures in interactions between ENSO and the North Pacific Oscillation. J. Climate, 15, 1295-1308.

— T. T. Barnett, and M. Latif, 2000: Connections between the Pacific Ocean tropics and midlatitudes on decadal timescales. J. Climate, 13, 1173-1194.

Power, S. B., 1995: Climate drift in a global OGCM. J. Phys. Oceanogr., 25, 1025-1036.

— , and R. A. Colman, 2006: Multi-year predictability in a coupled general circulation model. Climate Dyn., 26, 247272.

_ , R. Kleeman, F. Tseitkin, and N. Smith, 1995: A global version of the GFDL modular ocean model for ENSO studies. BMRC Tech. Rep., 18 pp.

— , F. Tseitkin, S. Torok, B. Lavery, R. Dahni, and B. McAvaney, 1998a: Australian temperature, Australian rainfall and the Southern Oscillation, 1910-1992: Coherent variability and recent changes. Aust. Meteor. Mag., 47, 85-101.

- _ - R. A. Colman, and A. Sulaiman, 1998b: A coupled general circulation model for seasonal prediction and climate change research. BMRC Research Rep. 66, 52 pp.

, T. Casey, C. Folland, A. Colman, and V. Mehta, 1999a: Interdecadal modulation of the impact of ENSO on Australia. Climate Dyn., 15, 319-324.

— , F. Tseitkin, V. Mehta, B. Lavery, S. Torok, and N. Holbrook, 1999b: Decadal climate variability in Australia during the twentieth century. Int. J. Climatol., 19, 169-184.

Ropelewski, C. F., and M. S. Halpert, 1987: Global and regional scale precipitation patterns associated with El Nino/Southern Oscillation. Mon. Wea. Rev., 115, 1606-1626.

Rotstayn, L. D., 1997: A physically based scheme for the treatment of stratiform clouds and precipitation in large-scale models. 1: Description and evaluation of the microphysical processes. Quart. J. Roy. Meteor. Soc., 123, 1227-1282.

Salinger, M. J., J. A. Renwick, and A. B. Mullan, 2001: Interdecadal Pacific Oscillation and South Pacific climate. Int. J. Climatol., 21, 1705-1721.

Schopf, P. S., and M. J. Suarez, 1988a: Vacillations in a coupled ocean-atmosphere model. J. Atmos. Sci., 45, 549-566.

$\longrightarrow$, and $-1988 \mathrm{~b}$ : A delayed action oscillator for ENSO. $J$. Atmos. Sci., 45, 3283-3287.

Schwarzkopf, M. D., and S. B. Fels, 1991: The simplified exchange method revisited: An accurate, rapid method for computa- tion of infrared cooling rates and fluxes. J. Geophys. Res., 96, 9075-9096.

Semtner, A. J., 1976: A model for the thermodynamics growth of sea ice in numerical investigations of climate. J. Phys. Oceanogr., 6, 379-389.

Smith, R. N. B., 1990: A scheme for predicting layer clouds and their water content in a general circulation model. Quart. J. Roy. Meteor. Soc., 116, 435-460.

Thompson, C. J., and D. S. Battisti, 2000: A linear stochastic dynamical model of ENSO. Part I: Model development. J. Climate, 13, 2818-2832.

Tiedtke, M., 1989: A comprehensive mass flux scheme for cumulus parameterization in large-scale models. Mon. Wea. Rev., 117, 1779-1800.

Timmerman, A., and F.-F. Jin, 2002: A nonlinear mechanism for decadal El Niño amplitude changes. Geophys. Res. Lett., 29, 1003, doi:10.1029/2001GL013369.

Tziperman, E., M. Cane, and H. Jarosh, 1994: El Niño chaos: Overlapping resonances between the seasonal cycle and the Pacific Ocean-atmosphere oscillator. Science, 264, 72-74.

Verdon, D. C., A. M. Wyatt, and S. W. Franks, 2004: Multi-decadal variability of rainfall and streamflow: Eastern Australia. Water Resour. Res., 40, W10201, doi:10.1029/2004WR003234.

Vimont, D. J., D. S. Battisti, and A. C. Hirst, 2002: Pacific interannual and interdecadal equatorial variability in a $1000-\mathrm{yr}$ simulation of the CSIRO coupled GCM. J. Climate, 15, 160178

Walland, D. J., S. B. Power, and A. C. Hirst, 2000: Decadal climate variability simulated in a coupled GCM. Climate Dyn., 16, 201-211.

Wang, B., and Y. Wang, 1996: Temporal structure of the Southern Oscillation as revealed by waveform and wavelet analysis. $J$. Climate, 9, 1586-1598.

Wang, C., 2001: A unified oscillator model for the El NiñoSouthern Oscillation. J. Climate, 14, 98-115.

Wang, G., R. Kleeman, N. Smith, and F. Tseitkin, 2000: Seasonal predictions with a coupled global ocean-atmosphere model. BMRC Research Rep. 77, 34 pp.

Wang, X. L., and C. F. Ropelewski, 1995: An assessment of ENSO-scale secular variability. J. Climate, 8, 1584-1599.

White, B. W., 2000: The importance of climate variability and seasonal forecasting to the Australian economy. Applcations of Seasonal Climate Forecasting in Agricultural and Natural Ecosystems-The Australian Experience, G. L. Hammer, N. Nicholls, and C. Mitchell, Eds., Kluwer, 1-22.

_, Y. M. Tourre, M. Barlow, and M. Dettinger, 2003: A delayed action oscillator shared by biennial, interannual, and decadal signals in the Pacific basin. J. Geophys. Res., 108, 3070, doi:10.1029/2002JC001490.

Working Group 2, 2004: ENSO decadal variability and subtropical/tropical interactions. Int. Workshop on the LowFrequency Modulation of ENSO, Toulouse, France, LEGOS/ GRGS/CNES, 14-16.

Working Group 3, 2004: Self-sustained low-frequency variability in the tropics. Int. Workshop on the Low-Frequency Modulation of ENSO, Toulouse, France, LEGOS/GRGS/CNES, $17-19$.

Wu, L., Z. Liu, R. Gallimore, R. Jacob, D. Lee, and Y. Zhong, 2003: Pacific decadal variability: The tropical Pacific mode and the North Pacific mode. J. Climate, 16, 3111-3131.

Wu, Z.-J., R. Colman, S. Power, X. Wang, and B. McAvaney, 2002: The El Niño Southern Oscillation Response in the BMRC Coupled GCM. BMRC Research Rep. 91, 18 pp. 